\title{
Ovopel and Carp Pituitary Extract as Spawning Inducers in Males of the Amazon Catfish Leiarius marmoratus (Gill, 1970)
}

\author{
João Ênio Xavier Souza Araújo ${ }^{1}$, Danilo Pedro Streit $\mathbf{J r}^{2}$, Janessa Sampaio de Abreu \\ Ribeiro $^{1}$, Edenilce de Fátima Ferreira Martins ${ }^{1}$, Francielle Novaes Souza ${ }^{1}$, Carlos Antonio \\ Lopes de Oliveira $^{3}$, Ricardo Pereira Ribeiro ${ }^{3}$, Nelson Mauricio Lopera-Barrero ${ }^{4}$ and Jayme \\ Aparecido Povh ${ }^{1^{*}}$ \\ ${ }^{1}$ Programa de Pós-Graduação em Ciência Animal; Universidade Federal de Mato Grosso; Cuiabá - MT - Brasil. \\ ${ }^{2}$ Departamento de Zootecnia; Universidade Federal do Rio Grande do Sul; Porto Alegre - RS - Brasil. \\ ${ }^{3}$ Departamento de Zootecnia; Universidade Estadual de Maringá, Maringá - PR - Brasil. ${ }^{4}$ Departamento de \\ Zootecnia; Universidade Estadual de Londrina; Londrina - PR - Brasil
}

\begin{abstract}
The objective of this study was to evaluate Ovopel and carp pituitary extract as spawning inducers in the males of the Amazon catfish L. marmoratus. The following treatments, applied in a single dose, were studied: 0.2, 0.4 and 0.6 Ovopel pellet/kg live weight, and $2.5 \mathrm{mg}$ carp pituitary extract/kg live weight. Each treatment was repeated four times. No significant difference in sperm volume, motility and vigor, time of motility, sperm count, or percentage of normal and abnormal spermatozoa was observed between the treatments. There was also no significant difference in terms of primary or secondary sperm defects, except for the secondary defect of loose heads, which was less frequent in the treatments using 0.4 and 0.6 Ovopel pellet/kg live weight. It was concluded that Ovopel could replace carp pituitary extract for induction spawning in the males of the Amazon catfish L. marmoratus.
\end{abstract}

Key words: Fish breeding, hypophysation, semen of fish

\section{INTRODUCTION}

Leiarius marmoratus is a rheophilic and omnivorous species found in the Amazon basin. Particularly in the midwestern and northern states of Brazil, this species has been used to obtain hybrids by the crosses with Pseudoplatystoma spp. females. These hybrids are easily trained to consume dry ration and cannibalism is practically absent (Lopera-Barrero et al. 2011). These zootechnical characteristics are difficult to manage in the traditional hybrid, known as "ponto e virgula", which is obtained by the crosses of $P$. corruscans with $P$. reticulatum.

Rheophilic species do not spawn naturally in captivity because of the need to migrate for final maturation and release of gametes. Therefore, breeding of these species in the laboratories of fry production is only possible through the application of hormone induction techniques. This approach consists of the use of natural or synthetic hormones to induce ovulation and spermiation in the species of commercial interest.

The hormone most widely used for the breeding of rheophilic fish in Brazil is carp and salmon

*Author for correspondence: jayme.povh@ufms.br 
pituitary extract (Zaniboni Filho and Weingartner 2007). However, a less expensive and more efficient alternative for spawning induction in the fish is the combination of gonadotrophin-releasing hormones (mGnRHa and sGnRHa) and dopamine receptor blockers (pimozide, domperidone, and metoclopramide), called $\mathrm{GnRHa}+$ dopamine inhibitor. Among these hormone inducers, Ovopel ${ }^{\circledR}$ is a synthetic product developed by the University of Godollo in Hungary, which consists of the mammalian GnRH analog, [D-Ala ${ }^{6}, \mathrm{Pro}^{9}$ NEt] LHRH, and the dopamine antagonist, metoclopramide, at concentrations of $18-20 \mu \mathrm{g}$ and 9-10 mg, respectively (Das 2004).

Semen quality is fundamental for breeding since males contribute significantly to reproductive and productive efficiency through their genetic input, as well as the fact that males are subjected to more and faster selection pressures. Sperm parameters such as concentration, volume, vigor, motility and percentage of viable cells are important to achieve high fertilization rates (Varela Junior et al. 2012). According to Streit $\mathrm{Jr}$ et al. (2008), these parameters together with sperm defects have been used as qualitative and quantitative semen criteria and as indicators of fertilizing ability.

In Brazil, no specific breeding protocol exists for L. marmoratus and the protocol commonly used in other species shows unsatisfactory results in terms of spawning induction. The objective of the present study was to evaluate Ovopel and carp pituitary extract as spawning inducers in the males of the Amazon catfish L. marmoratus.

\section{MATERIAL AND METHODS}

Twenty L. marmoratus males, with an average weight of $2.54 \mathrm{~kg}$ and mean age of three years, obtained from a fish farm in Mato Grosso, midwest region of Brazil, were used in the study. This sample was within the standard used by other authors (Das 2004; Mira-Lopes et al. 2010; Streit Jr. et al. 2012). The males were placed in a $500-\mathrm{m}^{2}$ tank and were fed twice daily commercial ration containing $32 \%$ crude protein $(\mathrm{g} / \mathrm{kg}$, ether extract 40 , mineral matter 130 , crude fiber 70 , calcium 35 , phosphorus 9, and vitamin C $100 \mathrm{mg} / \mathrm{kg}$ ). The animals were weighed, identified with a microchip and housed in 2,000 liter tanks with continuous water flow at an average temperature of $26.5^{\circ} \mathrm{C}$. Carp pituitary extract (CPE) and Ovopel were used as spawning inducers: $0.2,0.4$ and 0.6 Ovopel pellet $/ \mathrm{kg}$ live weight, and $2.5 \mathrm{mg} \mathrm{CPE} / \mathrm{kg}$ live weight. A single dose was applied per treatment, as recommended for male fish breeding (Zaniboni Filho and Weingartner 2007). After 180 degreehours, the animals were anesthetized with benzocaine $(20 \mathrm{mg} / \mathrm{L})$ for $5 \mathrm{~min}$. Next, semen was collected from all the animals with individual syringes (Billard et al. 1995) and immediately stored at $8^{\circ} \mathrm{C}$ for subsequent analysis. In the control group, males received saline solution instead of the hormone and were submitted to the same procedures as described for the animals treated with the spawning inducers.

For qualitative analysis, a $5 \mu \mathrm{L}$ semen sample was mounted on a microscope slide and activated with water. The following parameters were evaluated under a light microscope (40X): progressive sperm motility (0 to $100 \%$ ), sperm vigor (0 to 5 points), and time of motility (seconds). For quantitative analysis, semen volume was determined with a 0.1 $\mathrm{mL}$ graded syringe. Sperm count was determined by diluting $5.0 \mu \mathrm{L}$ of the semen sample in $25 \mathrm{~mL}$ buffered formal saline (1:5000) and spermatozoa were counted in a Neubauer chamber with $10 \mu \mathrm{L}$ diluent (semen + buffered formal saline) under a light microscope (20X). Sperm morphology was evaluated in the smears of the diluents (semen + buffered formal saline) stained with Rose Bengal as described by Streit Jr et al. (2008). The microscope slide containing the smears was dried and examined under a phase-contrast microscope at $40 \mathrm{X}$ magnification. Two hundred spermatozoa were analyzed and classified as normal and primary pathologies (bent, coiled, crooked tail, crooked head, small head, giant head, and twin tail). The secondary pathologies investigated were shoe-hook, headless, tailless and immature spermatozoa according to Herman et al. (1994).

A completely randomized design consisting of four treatments (three treatments with Ovopel and one treatment with CPE), one control (absence of hormone), and four repetitions was used for a total of 20 experimental units. The results were analyzed using the Statistical Analysis System package (SAS, 2006). The PROC GLM procedure of the SAS program was used for the statistical analysis of sperm volume, time of motility, and sperm count. Analysis of sperm volume included the effect of animal weight and treatments. For sperm count, the effect of sperm volume was considered as an additional variable. Sperm motility and vigor were analyzed using a gamma distribution with a logit link function implemented 
in the PROC GENMOD procedure of the SAS package. The effects of treatment on the occurrence of normal and abnormal sperm and primary and secondary defects were determined with the PROC GENMOD procedure of the SAS package using a Poisson distribution and logit link function. The following statistical tests were used for the comparison of means: Tukey test for sperm volume, time of motility, and sperm count; $t$-test for sperm motility, vigor, and percentage of normal spermatozoa and spermatozoa with primary (broken tail, coiled tail, short tail, macrocephaly) and secondary defects (folded tail, loose tail, loose head, cytoplasmic drop, and distal drop). These tests are implemented in the PROC GLM and PROC GENMOD procedures, respectively.

\section{RESULTS AND DISCUSSION}

Table 1 shows the semen volume, time of motility, sperm motility, sperm vigor and sperm count of $L$. marmoratus males induced to spawn with Ovopel and CPE. No significant differences in any of these parameters were observed between the treatments. Control males (absence of hormone) did not release semen and were excluded from the analysis. This species rarely releases semen without hormone induction, possibly because of the lack of domestication of broodstocks since the exploration of this fish is relatively new in Brazil. Lopera-Barrero et al. (2011) reported difficulty in obtaining semen from L. marmoratus without hormone induction.

Table 1 - Semen parameters of Leiarius marmoratus induced to spawn with Ovopel and carp pituitary extract (CPE).

\begin{tabular}{|c|c|c|c|c|c|}
\hline Treatment & Volume $(\mathrm{mL})^{1}$ & Motility $(\%)^{2}$ & Vigor $^{2,3}$ & Time of motility $(\mathrm{s})^{1}$ & $\begin{array}{c}\text { Sperm count } \\
(\text { spermatozoa } / \mathrm{mL})^{1}\end{array}$ \\
\hline \multicolumn{6}{|c|}{ Ovopel (pellet/kg) } \\
\hline 0.2 & 1.33 & 51.67 & 2.25 & 89.25 & $2.92 \times 10^{9}$ \\
\hline 0.4 & 1.23 & 60.00 & 3.00 & 86.00 & $2.20 \times 10^{9}$ \\
\hline 0.6 & 1.70 & 60.00 & 2.50 & 95.75 & $3.72 \times 10^{9}$ \\
\hline \multicolumn{6}{|l|}{ CPE (mg/kg) } \\
\hline 2,5 & 1.53 & 66.66 & 3.25 & 91.00 & $3.68 \times 10^{9}$ \\
\hline Overall mean & 1.45 & 59.58 & 2.73 & 90.78 & $3.13 \times 10^{9}$ \\
\hline
\end{tabular}

${ }^{1}$ Nonsignificant effect by the Tukey test at the $5 \%$ level. ${ }^{2}$ Nonsignificant effect by the $t$-test at the $5 \%$ level. ${ }^{3}$ Score of 0 to 5 .

A higher mean semen volume $(2.33 \mathrm{~mL})$ than that obtained in the present study was reported by Mira-López et al. (2010) for the same species using $\mathrm{CPE}$ and Ovaprim ${ }^{\circledR} \quad$ (sGnRHa + domperidone) as spawning inducers, but the authors also found no significant differences between the treatments. Although these authors used different hormone treatments, other factors might have also influenced the higher semen volume, such as time of domestication (the exploration of $L$. marmoratus started recently in Brazil), climate conditions, and breeding season.

Mean sperm motility (59.58\%) of L. marmoratus treated with the different spawning inducers was low when compared to that reported by MiraLópez et al. (2010) for the same specie $(89.0 \%)$ and for other species (Streit Jr et al. 2008; Povh et al. 2010; Maria et al. 2011; Streit Jr et al. 2012). In addition, no reference range of sperm motility was available for $L$. marmoratus in Brazil. The analysis adopted in this study for sperm motility, sperm vigor and time of motility was the first record for the species for which methods were adopted for the analysis of these parameters. Varela Junior et al. (2012) also used classical methods for the analysis of the same parameters. The use of a computer program such as Computer-Assisted Sperm Motility Analysis (CASA) for $L$. marmoratus requires prior standardization of semen samples for later use in the same analysis. Thus, the classical method was the alternative available for this study.

Sperm vigor and time of motility vary widely among the Neotropical fish species. Although no reference range of these parameters existed for $L$. marmoratus in Brazil, the present results were within the range reported for this species by MiraLopes et al. (2010) and other fish species by Streit Jr et al. (2012). The concentration of spermatozoa is a fundamental parameter for artificial reproduction of rheophilic fish (Streit $\mathrm{Jr}$ et al. 2012). In the present study, the mean 
concentration was $3.13 \times 10^{9}$ spermatozoa/mL and no significant difference was observed between the treatments (Table 1). Mira-Lopes et al. (2010) found a similar sperm concentration for the same species $\left(3.56 \times 10^{9}\right.$ spermatozoa $\left./ \mathrm{mL}\right)$. However, these authors reported a higher semen volume than that observed in the present study. Morphological analysis revealed no significant difference between the treatments for the parameters percentage of normal (mean of $87.43 \%$ ) and abnormal (12.57\%) sperm (Table 2).

There were no significant differences in the frequency of primary or secondary sperm defects between the treatments, with primary defects being more frequent $(8.7 \%)$ than secondary defects (3.87\%) (Table 3).

Table 2 - Percentage of normal and abnormal sperm in Leiarius marmoratus induced to spawn with Ovopel and carp pituitary extract (CPE).

\begin{tabular}{lcc}
\hline \multirow{2}{*}{ Treatment } & \multicolumn{2}{c}{ Spermatozoa (\%) } \\
\cline { 2 - 3 } & Normal $^{\mathbf{1}}$ & Abnormal $^{\mathbf{1}}$ \\
\hline Ovopel (pellet/kg) & & \\
0.2 & 84.87 & 15.13 \\
0.4 & 87.50 & 12.50 \\
0.6 & 89.37 & 10.63 \\
CEP (mg/kg) & & \\
$\quad 2.5$ & 88.00 & 12.00 \\
\hline Overall mean & 87.43 & 12.57 \\
\hline
\end{tabular}

${ }^{1}$ Nonsignificant effect by the $t$-test at the $5 \%$ level.

Table 3 - Percentage of sperm defects in Leiarius marmoratus induced to spawn with Ovopel and carp pituitary extract (CPE).

\begin{tabular}{|c|c|c|}
\hline & $\begin{array}{c}\text { Primary } \\
\text { defects }(\%)^{1,2}\end{array}$ & $\begin{array}{c}\text { Secondary } \\
\text { defects }(\%)^{1,2}\end{array}$ \\
\hline \multicolumn{3}{|c|}{ Ovopel (pellet/kg) } \\
\hline 0.2 & 10.63 & 4.50 \\
\hline 0.4 & 9.17 & 3.33 \\
\hline 0.6 & 8.25 & 2.38 \\
\hline \multicolumn{3}{|l|}{ CPE (mg/kg) } \\
\hline 2.5 & 6.88 & 5.13 \\
\hline Overall mean & 8.70 & 3.87 \\
\hline
\end{tabular}

${ }^{1}$ Percentage of primary and secondary defects in relation to the total number of spermatozoa analyzed.

${ }^{2}$ Nonsignificant effect by the $t$-test at the $5 \%$ level.

No significant difference in the primary sperm defects was observed between the treatments, with a higher incidence of coiled tails $(69.87 \%)$, followed by broken tails (17.44\%), short tails $(12.25 \%)$, and macrocephaly $(0.44 \%)$. The origin of primary defects in the sperm cells might be related to nutritional deficiencies, age of the animals, consanguinity, and male diseases (Herman et al. 1994). Likewise, no significant difference in secondary sperm defects was observed between the treatments, with a higher incidence of folded tails (46.44\%) and loose heads $(38.66 \%)$, followed by loose tails $(6.26 \%)$, cytoplasmic drops (5.62\%), and distal drops (3.02\%). A significant difference was only in the frequency of loose heads, which was lower in the treatments with 0.4 and 0.6 Ovopel pellet $/ \mathrm{kg}$ live weight (10.32 and $41.67 \%$, respectively). A number of studies have shown high frequencies of secondary sperm defects in fish, particularly loose heads and tails (Streit Jr et al. 2008; Maria et al. 2011). These high frequencies of secondary abnormalities might be related to the procedure of smear preparation or semen collection, environmental temperature, diseases, animal feeding and sperm duct problems (Herman et al. 1994). Therefore, the higher frequency of loose heads in the treatments with 0.2 Ovopel pellet $/ \mathrm{kg}$ live weight and with CPE could be a consequence of inadequate slide preparation. Nevertheless, a breeding protocol is needed for male fish that permits rapid and consistent assessment. In this case, the detection of sperm pathologies is practical and easy and this information can be added to the remaining data for the qualitative evaluation of fish semen. Structural analysis of spermatozoa (cell membrane rupture and mitochondrial and DNA damage) is more precise, but is more time consuming and costly.

An inverse correlation exists between sperm motility and sperm defects. In this respect, an increase in the percentage of sperm defects results in reduced motility since these defects can limit the motility and vigor of spermatozoa and thus interfere with fertilization rates (Cosson et al. 1999). Although not significant, the present results suggested a higher chance of normal sperm if the concentration of the spawning inducer Ovopel was increased.

\section{CONCLUSIONS}

In conclusion, the present results suggested that Ovopel, at the concentrations tested, could replace the protocol with carp pituitary extract for spawning induction in the males of the Amazon catfish L. marmoratus. 


\section{ACKNOWLEDGEMENTS}

We thank Coordenação de Aperfeiçoamento de Pessoal de Nível Superior (CAPES) for the Master's fellowship granted; Piscicultura Buriti Nova Mutum (MT) for the infrastructure, animals and technical support that permitted the study, and the state funding agency Fundação de Amparo à Pesquisa do Estado de Mato Grosso (FAPEMAT) for financial support.

\section{REFERENCES}

Billard R, Cosson J, Crim LW, Suquet M. Sperm physiology and quality. In: Bromage NR, Roberts RJ, editors. Broodstock management and egg and larval quality. Oxford: Blackwell Science; 1995. p. 25-52.

Cosson J, Dreanno C, Billard R, Suquet M, Cibert C. Regulation of axonemal wave parameters of fish spermatozoa by ionic factors. In: Gagnon C, editor. The male gamete: From basic science to clinical applications. Montréal: Cache River Pres; 1999. p. 161-186.

Das SK. Evaluation of a new spawning agent, Ovopel in induced breeding of indian carps. Asian Fish Sci. 2004; 17: 313-322.

Herman HA, Mitchell JR, Doak GA. The artificial insemination and embryo transfer of dairy and beef cattle. Illinois: Interstate Publishers, 1994, 392p.

Lopera-Barrero NM, Ribeiro RP, Povh JA, Mendez LDV, Poveda-Parra AR. Produção de organismos aquáticos - uma visão geral no Brasil e no mundo. Guaíba: Agrolivros, 2011, 320p.

Maria AM, Azevedo HC, Santos JP, Carneiro PCF. Hormonal induction and semen characteristics of tambaqui Colossoma macropomum. Zygote. 2011; 20: $39-43$.
Mira-López TM, Medina-Robles VM, Cruz-Casallas, PE. Evaluación de tres protocolos hormonales para la inducción de la espermiación en yaque Leiarius marmoratus. Rev MVZ Córdoba. 2010; 15: 20702077.

Povh JA, Ribeiro RP, Sirol RN, Streit Jr DP, Moreira HL, Siewerdt F, et al. Microsatellite analysis of the parental contribution of Piaractus mesopotamicus to the production of offspring in the semi-natural system of reproduction. Braz Arch Biol Technol. 2010; 53: 389-396.

SAS Institute, SAS Technical Report. SAS/STAT software: Changes and Enhancement, Release 9.1.1.3 Cary NC: SAS Institute, 2006.

Streit Jr DP, Sirol RN, Ribeiro RP, Digmayer M, Galo JM, Moraes GV, et al. Parâmetros seminais de reprodutores de Pseudoplatystoma reticulatum, em cativeiro, pré e pós-indução hormonal. Rev Bras Reprod Anim. 2012; 36: 188-193.

Streit Jr DP, Sirol RN, Ribeiro RP, Moraes GV, Vargas LDM, Watanabe AL. Qualitative parameters of the piapara semen (Leporinus elongatus Valenciennes, 1850). Braz J Biol. 2008; 68: 373-377.

Varela Junior AS, Corcini CD, Gheller SMM, Jardim RD, Lucia T, Streit Jr DP, et al. Use of amides as cryoprotectants in extenders for frozen sperm of tambaqui, Colossoma macropomum. Theriogenology. 2012; 78(2): 244-251.

Zaniboni Filho E, Weingartner M. Técnicas de indução da reprodução de peixes migradores. Rev Bras Reprod Anim. 2007; 31: 367-373.

Received: October 03, 2013; Accepted: June 26, 2014 